\title{
Active Surveillance as an Effective Management Option for Low-Risk Papillary Thyroid Microcarcinoma
}

\author{
Min Ji Jeon, Won Gu Kim, Tae Yong Kim, Young Kee Shong, Won Bae Kim \\ Department of Internal Medicine, Asan Medical Center, University of Ulsan College of Medicine, Seoul, Korea
}

Active surveillance (AS) for low-risk papillary thyroid microcarcinoma (PTMC) has been accepted worldwide as safe and effective. Despite the growing acceptance of AS in the management of low-risk PTMCs, there are barriers to AS in real clinical settings, and it is important to understand and establish appropriate AS protocol from initial evaluation to follow-up. PTMC management strategies should be decided upon after careful consideration of patient and tumor characteristics by a multidisciplinary team of thyroid cancer specialists. Patients should understand the risks and benefits of AS, participate in decision-making and follow structured monitoring strategies. In this review, we discuss clinical outcomes of AS from previous studies, optimal indications and follow-up strategies for $\mathrm{AS}$, and unresolved questions about AS.

Keywords: Thyroid neoplasms; Papillary thyroid microcarcinoma; Watchful waiting

\section{INTRODUCTION}

Active surveillance (AS) for low-risk papillary thyroid microcarcinoma (PTMC) was first introduced in the early 2000s [1-3] and it now has been universally accepted as an alternative to immediate surgery for low-risk PTMC [4-7]. Low-risk PTMC is generally defined as PTMCs without clinically evident metastases or local invasion [4]. AS is life-long structured follow-up to evaluate changes in disease status [8]. In cases of disease progression, such as tumor growth or the development of new metastases, patients must undergo appropriate treatment, including surgery. A recent meta-analysis of AS for low-risk PTMCs determined the 5-year incidence of tumor enlargement $\geq 3 \mathrm{~mm}$ to be $5.3 \%$ and that of new lymph node (LN) metastasis to be $1.6 \%$ [6]. These findings suggest AS as a safe and effective management option for low-risk PTMCs and recent clinical guidelines also have suggested AS as a management option for

Received: 25 March 2021, Revised: 3 June 2021, Accepted: 28 June 2021

Corresponding author: Won Bae Kim

Department of Internal Medicine, Asan Medical Center, University of Ulsan College of Medicine, 88 Olympic-ro 43-gil, Songpa-gu, Seoul 05505, Korea Tel: +82-2-3010-3913, Fax: +82-2-3010-6962, E-mail: kimwb@amc.seoul.kr patients with low-risk PTMCs based on this evidence $[4,9,10]$.

Despite the growing acceptance of AS in the management of low-risk PTMCs, there are barriers to AS in real clinical settings: many variables to consider at the time of the management decision, patient and physician worries about disease progression, and concerns about loss to follow-up [11]. To safely and effectively implement AS in the management of PTMCs, clinicians must understand the various aspects of AS and require guidance about how and when to choose AS. In this review, we discuss clinical outcomes of AS from previous studies, optimal indications and follow-up strategies for AS, and unresolved questions about AS.

\section{CLINICAL OUTCOMES OF AS FROM PREVIOUS STUDIES}

Many prospective and retrospective analyses have been report-

Copyright $\odot 2021$ Korean Endocrine Society

This is an Open Access article distributed under the terms of the Creative Commons Attribution Non-Commercial License (https://creativecommons.org/ licenses/by-nc/4.0/) which permits unrestricted non-commercial use, distribution, and reproduction in any medium, provided the original work is properly cited. 
ed and representative studies on AS for PTMC are listed in Table 1 [12-16]. Two Japanese centers conducted prospective trials of AS for PTMCs in the 1990s and proposed AS for low-risk PTMCs as a safe management option. The landmark study from Kuma Hospital in Japan defined a low-risk PTMC as a cytologically diagnosed papillary thyroid carcinoma (PTC) measuring $10 \mathrm{~mm}$ or less by ultrasonography (US), with no clinical evidence of metastasis, no invasion of the recurrent laryngeal nerve (RLN) or trachea, also not located adjacent to the RLN or trachea, and no high-grade malignancy detected by cytopathologic examination. Patients were followed-up with periodic US once or twice per year. Disease progression during AS was defined as follows: significant enlargement (diameter increase $\geq 3 \mathrm{~mm}$ relative to the initial evaluation), or the appearance of new regional LN metastasis. During a median of 60 months of follow-up of 1235 patients, significant tumor enlargement was observed in 58 patients (4.6\%), and new LN metastases were observed in 19 patients $(1.5 \%)$, including 15 patients with newly developed lateral neck LN metastasis [12]. Similar findings were reported from a study conducted at Cancer Institute Hospital in Japan, which included patients with cytologically diagnosed asymptomatic PTMC (clinical T1aN0M0 by the American Joint Committee on Cancer tumor-node-metastasis staging). During a mean of 6.8 years of follow-up of 384 patients with 480 PTMC

Table 1. Summary of Representative Clinical Studies About Active Surveillance for Thyroid Cancer

\begin{tabular}{|c|c|c|c|c|c|c|}
\hline Center & $\begin{array}{l}\text { Publication } \\
\text { year } \\
\text { (reference) }\end{array}$ & $\begin{array}{c}\text { No. of patients } \\
\text { (enrolled } \\
\text { period) }\end{array}$ & Inclusion \& exclusion criteria & $\begin{array}{l}\text { Follow-up duration } \\
\quad \& \text { strategies }\end{array}$ & $\begin{array}{c}\text { Tumor maximal } \\
\text { diameter } \\
\text { enlargement } \\
(\geq 3 \mathrm{~mm})\end{array}$ & $\begin{array}{c}\text { Development } \\
\text { of new LN } \\
\text { metastasis }\end{array}$ \\
\hline $\begin{array}{l}\text { Kuma } \\
\text { hospital, } \\
\text { Japan }\end{array}$ & 2014 [12] & $\begin{array}{l}\text { 1,235 Patients } \\
(1993-2011)\end{array}$ & $\begin{array}{l}\text { PTMC }(\leq 1 \mathrm{~cm}) \text { without } \\
\text { Regional LN metastasis or distant metastases } \\
\text { Signs or symptoms of invasion to the RLN or } \\
\text { trachea } \\
\text { FNAB findings suggesting high-grade malignancy } \\
\text { Tumors located adjacent to the RLN or trachea } \\
\text { Patients under observation } \geq 18 \text { months }\end{array}$ & $\begin{array}{l}\text { Mean } 60 \text { months } \\
\text { US } 1-2 / \text { year }\end{array}$ & $\begin{array}{l}58 \text { Patients } \\
(4.6 \%)\end{array}$ & $\begin{array}{l}19 \text { Patients } \\
(1.5 \%)\end{array}$ \\
\hline $\begin{array}{l}\text { Cancer } \\
\text { Institute } \\
\text { Hospital, } \\
\text { Japan }\end{array}$ & 2016 [13] & $\begin{array}{l}384 \text { Patients, } \\
480 \text { lesions } \\
(1995-2013)\end{array}$ & $\begin{array}{l}\text { Clinical T1aN0M0 } \\
\text { Patients on follow-up } \geq 12 \text { months }\end{array}$ & $\begin{array}{l}\text { Mean } 6.8 \text { years } \\
\text { Palpation, US, chest } \\
\text { radiography, or CT } \\
\text { every } 6 \text { or } 12 \\
\text { months }\end{array}$ & $\begin{array}{l}29 \text { Lesions } \\
(6.0 \%)\end{array}$ & $\begin{array}{l}4 \text { Patients } \\
\quad(1.0 \%)\end{array}$ \\
\hline $\begin{array}{c}\text { MSKCC, } \\
\text { United } \\
\text { States }\end{array}$ & $2017[14]$ & $\begin{array}{l}\text { Total } 291 \\
\text { patients: } 232 \\
\text { patients } \\
\text { ( } \leq 1 \mathrm{~cm} \text { only) } \\
\text { (period not } \\
\text { reported) }\end{array}$ & $\begin{array}{l}\text { PTC }(\leq 1.5 \mathrm{~cm}) \text { without } \\
\text { Clinical or radiological evidence of ETE, invasion } \\
\text { of local structures, or regional or distant } \\
\text { metastases } \\
\text { Patients having TSH level within the reference } \\
\text { interval and under observation } \geq 6 \text { months }\end{array}$ & $\begin{array}{l}\text { Median } 25 \text { months } \\
\text { US every } 6 \text { months } \\
\text { for } 2 \text { years, then } \\
\text { yearly }\end{array}$ & $\begin{array}{l}11 \text { Patients } \\
(3.8 \%) \\
9 \text { Patients } \\
(3.9 \%) \text { among } \\
\text { patients with } \\
\leq 1 \mathrm{~cm} \text { PTC }\end{array}$ & 0 \\
\hline $\begin{array}{l}\text { Multicenter, } \\
\text { South } \\
\text { Korea }\end{array}$ & 2018 [15] & $\begin{array}{l}370 \text { Patients } \\
\quad(2002-2017)\end{array}$ & $\begin{array}{l}\text { PTMC }(\leq 1 \mathrm{~cm}) \text { without } \\
\text { Initial lateral LN metastasis or distant metastases } \\
\text { Clinical evidence of macroscopic invasion into the } \\
\text { perithyroidal soft tissue, trachea or the RLN } \\
\text { FNAB or CNB findings suggesting aggressive } \\
\text { variants of PTC } \\
\text { Patients on follow-up } \geq 12 \text { months }\end{array}$ & $\begin{array}{l}\text { Median } 32.5 \text { months } \\
\text { PEx and US every } 6 \\
\text { or } 12 \text { months }\end{array}$ & $\begin{array}{l}13 \text { Patients } \\
(3.5 \%)\end{array}$ & $\begin{array}{l}5 \text { Patients } \\
(1.4 \%)\end{array}$ \\
\hline $\begin{array}{l}\text { University } \\
\text { Hospital } \\
\text { of Pisa, } \\
\text { Italy }\end{array}$ & $2020[16]$ & $\begin{array}{l}93 \text { Patients } \\
\text { (2014-2018) }\end{array}$ & $\begin{array}{l}\text { Single PTC }(\leq 1.3 \mathrm{~cm}) \text { without } \\
\text { Clinical or radiological evidence of ETE, invasion } \\
\text { of local structures, or regional or distant } \\
\text { metastases } \\
\text { Thyroid dysfunction }\end{array}$ & $\begin{array}{l}\text { Median } 19 \text { months } \\
\text { US and laboratory } \\
\text { examination every } \\
6 \text { months for } 2 \\
\text { years, then yearly }\end{array}$ & $\begin{array}{l}2 \text { Patients } \\
(2.2 \%)\end{array}$ & $\begin{array}{l}1 \text { Patient } \\
(1.1 \%)\end{array}$ \\
\hline
\end{tabular}

LN, lymph node; PTMC, papillary thyroid microcarcinoma; RLN, recurrent laryngeal nerve; FNAB, fine needle aspiration biopsy; US, ultrasonography; CT, computed tomography; MSKCC, Memorial Sloan Kettering Cancer Center; PTC, papillary thyroid carcinoma; ETE, extrathyroidal extension; TSH, thyroid-stimulating hormone; CNB, core-needle biopsy; PEx, physical examination. 
lesions, significant enlargements $\geq 3 \mathrm{~mm}$ and new cervical LN metastasis were detected in 29 lesions $(6.0 \%)$ and four patients $(1.0 \%)$, respectively [13].

A retrospective study from the United States analyzed 291 low-risk PTCs $\leq 1.5 \mathrm{~cm}$ in diameter undergoing AS. As in previous studies, only PTCs without any clinical or radiological evidence of extrathyroidal extension (ETE), invasion of local structures, or metastases were included, and the tumor diameter enlargements $\geq 3 \mathrm{~mm}$ were observed in only 11 patients $(3.8 \%)$ and there were no patients with newly developed LN metastases [14].

In a Korean multicenter study, AS of low-risk PTMCs, which were defined according to the Kuma Hospital criteria [12], was also associated with excellent outcomes. During a median of 33 months of follow-up of 370 patients, tumor diameter increase of $\geq 3 \mathrm{~mm}$ and new LN metastases were detected in $13(3.5 \%)$ and five $(1.4 \%)$ patients, respectively [15]. A recent study conducted in Italy found that only three patients $(3.2 \%)$ showed disease progression during median 19 months of AS for low-risk PTCs smaller than $1.3 \mathrm{~cm}$ : two with tumor enlargement and one with new LN metastasis [16].
From these studies, we learned that low-risk PTMCs could be safely observed without immediate surgery. The disease progression rate during AS is low, $3 \%$ to $7 \%$ during 2 to 7 years of follow-up, with tumor enlargement and new LN metastasis occurring independently from one other. Delayed surgery after AS was also not associated with poor clinical outcomes, such as recurrence or disease-specific mortality. These studies have also guided decision-making in terms of the patient and tumor characteristics that are amenable to AS, follow-up strategies, and the definition of disease progression during AS.

\section{OPTIMAL INDICATIONS FOR AS}

In general, AS is an option for any adult patient with low-risk PTMCs. However, various patient and tumor characteristics should be considered when thinking of optimal indications for AS (Fig. 1).

\section{Patient characteristics}

First of all, patients should understand the concept of AS and be compliant with AS follow-up plans [5,7]. Patient age at diagno-

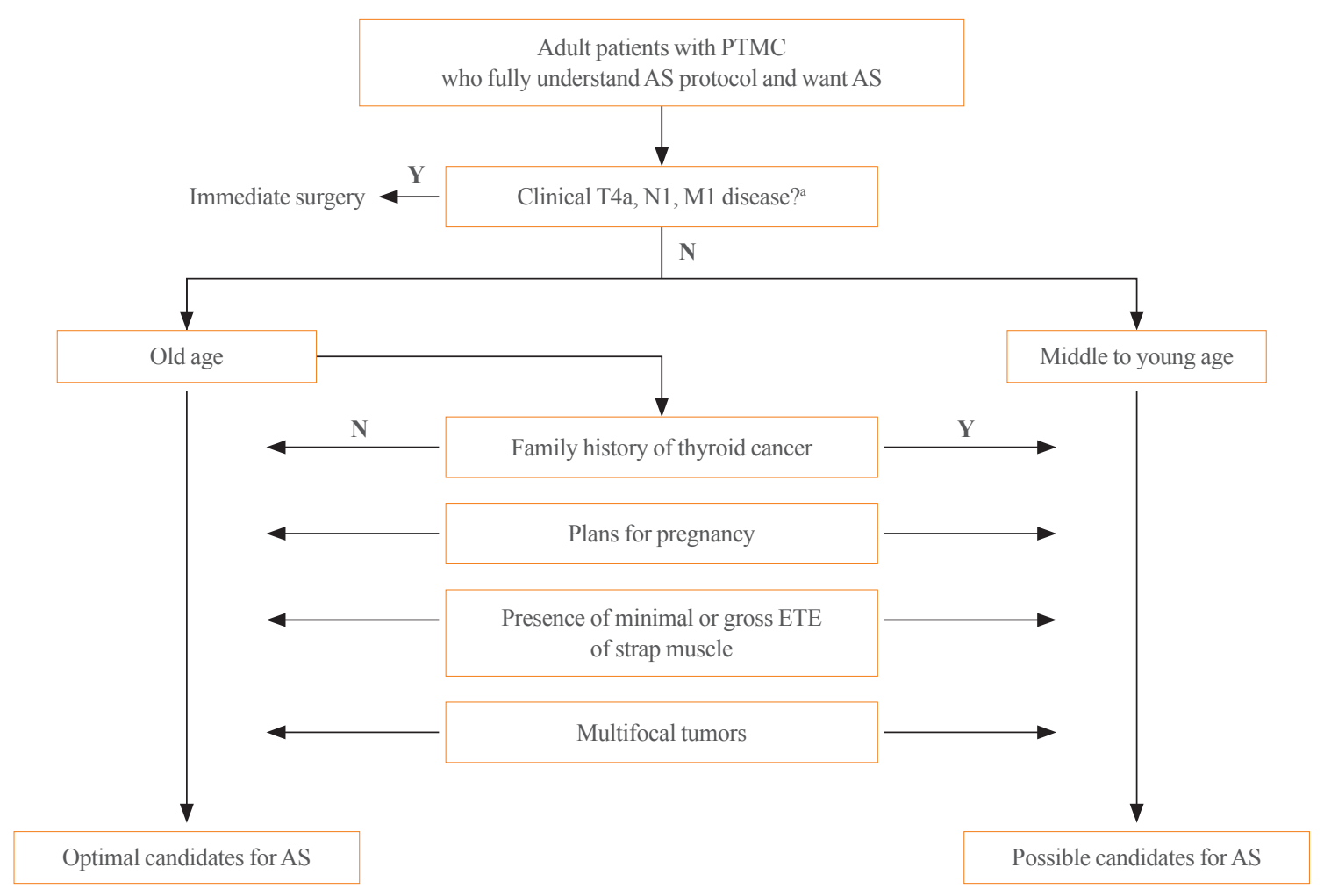

Fig. 1. Algorithm for assessing patient and tumor characteristics informing the decision to implement active surveillance (AS) of papillary thyroid microcarcinoma. PTMC, papillary thyroid microcarcinoma; ETE, extrathyroidal extension; Y, yes; N, no. ${ }^{a}$ T4a, N1, and M1 disease were defined according to the American Joint Committee on Cancer tumor-node-metastasis staging system. 
sis is the most important characteristic. Previous studies have shown both tumor enlargement and the development of new LN metastasis (i.e., PTMC progression), during AS to be significantly associated with patient age $[12,15,17]$. In these studies, PTMCs in young patients were more likely to be progressive than those in older patients. In a meta-analysis, the pooled risk ratio for tumor growth and new $\mathrm{LN}$ metastases in patients aged 40 to 50 years compared to younger ( $<40$ years) patients were 0.51 and 0.22 , respectively [18]. The lifetime disease progression probabilities were also significantly different according to the age at presentation: $60.3 \%$ among patients in their 20 s versus $3.5 \%$ among patients in their 70s [19]. These findings demonstrate why older patients (usually older than 60 years) are considered optimal candidates for AS [5,7].

Besides patient age, a family history of thyroid cancer and fertility planning need to be considered as patient characteristics [10]. Because patients with a familial history of thyroid cancer have been reported to have higher rates of bilateral multifocal tumors and LN metastasis than those with sporadic disease [20,21], familial PTMC might not be an optimal indication for AS. In terms of fertility planning, a previous study conducted at Kuma Hospital reported a higher rate of tumor enlargement among pregnant patients than control patients [22]. Therefore, AS of low-risk PTMCs is not suitable for women of childbearing age who plan to have children. However, a long-term follow-up study involving the entire AS cohort from Kuma Hospital did not find higher rates of disease progression during pregnancy: tumor enlargement occurred in only four out of 51 patients during pregnancy [23]. Our group also examined the clinical outcomes of PTC patients who had delayed surgery due to pregnancy, and there was no clinically significant disease progression during observation [24].

Even though younger low-risk PTMC patients with a familial history of thyroid cancer, or who plan on conceiving are not optimal candidates for AS, patients can select undergoing AS when they are fully informed and understand the risks of AS $[5,10]$.

\section{Tumor characteristics}

The presence of clinical LN metastasis (N1) or distant metastasis (M1), invasion to the RLN or trachea (T4a), and ETE are tumor characteristics that should be considered.

It is clear that PTMCs staged as clinical N1, M1, or T4a should undergo appropriate immediate surgery rather than AS because those are not low-risk PTMCs $[4,7,10]$. Neck US is generally used to evaluate these tumor characteristics. When US shows suspicious findings for LN metastasis, such as round enlargement, loss of the fatty hilum, hyperechogenicity, cystic changes, calcifications, or peripheral vascularity, fine-needle aspiration biopsy with the measurement of thyroglobulin in the washout fluid is needed to confirm metastasis [4]. A thyroid cancer forming an obtuse angle with the trachea or protruding into the tracheoesophageal groove as observed on US, is highly likely to have invaded the trachea or RLN $[25,26]$. Even though neck US is an effective tool for evaluating tumor status in PTMCs, neck computed tomography (CT) might have additional benefits for evaluating cervical LN metastasis or invasion of the trachea or RLN [27]. In a study from Korea that evaluated the diagnostic accuracy of neck US and CT for cervical LN metastases among PTMC patients, CT had a higher specificity and positivity predictive value for detecting cervical LN metastases [28]. However, routine chest CT is not recommended for the initial evaluation of PTMC patients starting AS [10]. The incidence of distant metastasis among PTMCs is very low [29] and some previous studies have failed to find any patients under AS of PTMCs with distant metastases. A recent study reported by Kawano et al. [30] found that routine chest CT for clinical T1aN0 PTCs did not detect any lung metastasis among 1,000 patients.

Except in the context of clinical T4a disease, the presence of minimal ETE or gross ETE to strap muscles (T3b) are not considered as definite indications for immediate surgery because delayed surgery after progression in such cases would not broaden the surgical extent [10]. US features of replacement of the strap muscle and capsular disruption have been shown to have high positive predictive values for predicting minimal or gross ETE to strap muscles [25], and AS can be considered in these cases after discussions about disease status and the risks of AS with the patient.

Although patients with solitary PTMCs have been regarded as optimal candidates for AS [7], no previous studies on AS for low-risk PTMCs have excluded multifocal tumors [12,31-33]. Furthermore, multifocality has been demonstrated to not be a risk factor for disease progression during AS [12]. Thus, patients with multifocal PTMCs can select AS.

Aggressive cytologic or histopathologic tumor characteristics have been demonstrated as contraindications to AS in previous studies [7,12,15]. Even though Tanaka et al. [34] suggested five cytological findings indicating the tall-cell variant of PTC, the cytohistological findings might be different from final histologic findings because the proportion of tall columnar cells in the final histology is important for diagnosing the tall-cell variant of 
PTC. Furthermore, the cytohistological findings of other aggressive variants are not known. Thus, these criteria might be unhelpful in real-world practice.

\section{OPTIMAL FOLLOW-UP OF PATIENTS DURING AS}

\section{Follow-up strategies}

According to the protocols of previous studies [12-14], regular US follow-up for monitoring tumor growth or the development of new LN metastases is recommended every 6 months for the initial 1 to 2 years and once a year thereafter. Tumor growth has been defined as an increase in maximal diameter by $\geq 3 \mathrm{~mm}$ [12]. When disease progression is confirmed, appropriate surgery is recommended. Some researchers have suggested that immediate surgery after disease progression is not always necessary because only $8 \%$ of PTMCs have demonstrated continued enlargement, with most remaining stable or even shrinking after the confirmation of disease progression [35]. The optimal timing for surgery after disease progression needs to be further evaluated.

\section{Prognostic factors for disease progression during AS}

Kwon et al. [31] were the first to report tumor volume (TV) change as a more sensitive marker for tumor enlargement during AS: TV enlargement $\geq 50 \%$ was detected in $14 \%$ of patients while maximal diameter increases $\geq 3 \mathrm{~mm}$ were detected only in $2 \%$ of patients under AS in their study. Tuttle et al. [14] also reported that PTCs appear to follow predictable growth kinetics when evaluated serially in terms of TV. Furthermore, tumor volume doubling time (TVDT) has been demonstrated as a good indicator of the growing velocity of PTCs: about $30 \%$ of patients under AS had TVDTs $<5$ years and all patients with maximal diameter increases $\geq 3 \mathrm{~mm}$ had TVDTs $<5$ years [36]. These findings suggest that the determination of TVDT using the initial 2 to 3 follow-up US findings may be helpful for selecting patients who finally need surgical management.

Kim et al. [37] reported that higher serum thyroid-stimulating hormone (TSH) levels are associated with TV increases and that the optimal TSH cutoff for predicting PTMC progression is 2.5 $\mathrm{mIU} / \mathrm{L}$. However, there was insufficient evidence supporting the role of TSH suppression therapy during AS. V-Raf murine sarcoma viral oncogene homolog $\mathrm{B}(B R A F)$ and telomerase reverse transcriptase (TERT) promoter mutations, either separately or in combination, are well-known as poor prognostic markers for PTC progression. However, there is no evidence support- ing their prognostic role in the progression of PTMC during AS. In a previous study evaluating surgical specimens from delayed surgery after AS, the rates of $B R A F$ mutations were not different between a stable disease group and a disease progression group (patients who experienced tumor enlargement or new LN metastases) and TERT promoter mutations were not detected in any tumors [38].

Unlike for tumor enlargement, there are no practical prognostic markers for predicting new LN metastasis during AS, except young age. Previous studies have found much lower rates of new LN metastases during AS compared with rates of tumor enlargement, and the number of metastases have been insufficient to evaluate prognostic markers. In a retrospective analysis of PTMCs with lateral neck LN metastasis, young age, male sex, upper lobe or subcapsular tumor location, and microcalcifications were significant risk factors for lateral neck LN metastasis [39].

\section{UNRESOLVED QUESTIONS ABOUT AS}

\section{Tumor size criteria for AS}

Initially, AS was applied for low-risk PTCs $\leq 1 \mathrm{~cm}$ measured by US; however, some studies have broadened this size cutoff. A study conducted at the Memorial Sloan Kettering Cancer Center in New York included PTCs $\leq 1.5 \mathrm{~cm}$ and demonstrated excellent clinical outcomes [14]. Sakai et al. [40] reported AS outcomes of T1bN0M0 PTCs. After a mean of 7.4 years of AS, disease progression was confirmed in six of 61 patients, and the rate was not significantly different from that of T1aN0M0 PTCs. However, Cheng et al. [41] reported that the tumor size $>1.5 \mathrm{~cm}$ has high risk of lymphovascular invasion and suggested a tumor size of $1.5 \mathrm{~cm}$ as a safe upper limit for AS. Further studies are needed to confirm the safety of AS for PTCs with maximal diameters of 1 to $2 \mathrm{~cm}$.

\section{Head-to-head comparison of clinical outcomes: AS vs. lobectomy}

AS is a safe and effective approach for the management of lowrisk PTMCs, but it has risks of disease progression, including the development of metastases, and patients require life-long regular monitoring of disease status. A lobectomy, which is recommended as a standard surgical treatment for low-risk PT$\mathrm{MCs}$, is also safe and effective; the risk of recurrence including contralateral lobe recurrence has been estimated to be $3.8 \%$ during 8.5 years of follow-up, and the incidence of postoperative complications has been estimated as 1\% [42]. Prospective stud- 
ies comparing the clinical outcomes of AS with immediate lobectomy for low-risk PTMCs are warranted. Recently the Korean Multicenter Prospective Cohort Study of Active Surveillance or Surgery (KoMPASS) for low-risk PTMCs was initiated, and the results of this study will help confirm the role of AS and develop individualized management strategies for low-risk PTMCs. This study aims to compare clinical outcomes including disease progression rate, quality-of-life variables, and cost-effectiveness, between the two management strategies [43].

\section{Localized treatment for PTMCs}

The safety and effectiveness of US-guided ablation therapies, such as microwave ablation (MWA) or radiofrequency ablation (RFA) for PTMCs, have been evaluated in many previous studies [44], and relatively long-term follow-up data were recently reported. Teng et al. [45] reported the 5-year follow-up data of 41 PTMCs managed with MWA and reported a 99\% TV reduction rate without any recurrences or confirmed metastases. Cho et al. [46] reported the mean 6-year follow-up data of 84 PTMCs that underwent RFA. Complete disappearance rates of $100 \%$ were achieved at 60 months of follow-up, and there were no cases of local tumor progression or newly developed metastasis. There were four newly developed cancers during followup, and these were all treated by additional RFAs [46]. In both studies, complication rates associated with ablation were minimal and transient. These data suggest that localized ablative therapies are effective and safe approaches to PTMC treatment. Localized ablative therapies might be superior to AS in that it can ensure primary tumor control and also be superior to surgical treatment with low complication rates. Further data from prospective comparative studies are needed (NCT04197960, NCT03377829).

\section{CONCLUSIONS}

Based on many prospective and retrospective studies showing favorable outcomes from AS for low-risk PTMCs, AS has been accepted as one of the standard management strategies for lowrisk PTMCs worldwide. Over half of the patients with low-risk PTMC captured by a recent survey in Japan have been undergoing AS [10]. It is estimated that there will be 60,000 to 80,000 AS candidates in the United States in the next 5 years [47]. For the appropriate implementation of AS in such a large volume of patients, it is important to establish appropriate AS protocols.

Choosing AS is not just as simple as a decision to avoid surgery. The decision should be made after careful consideration of patient and tumor characteristics by a multidisciplinary team of thyroid cancer specialists. Patients should understand the risks and benefits of AS and be involved in the decision-making process. This might also be helpful for patient compliance with a life-long follow-up strategy. AS of low-risk PTMC is safe and effective when correctly implemented. Further studies are needed to determine the long-term clinical outcomes of AS in comparison with immediate surgery.

\section{CONFLICTS OF INTEREST}

No potential conflict of interest relevant to this article was reported.

\section{ACKNOWLEDGMENTS}

This research was supported by a grant of the Korea Health Technology R\&D Project through the Korea Health Industry Development Institute (KHIDI), funded by the Ministry of Health \& Welfare, Republic of Korea (grant number: HC19C0481, HC19C0215).

\section{ORCID}

Min Ji Jeon https://orcid.org/0000-0002-1297-107X

Won Bae Kim https://orcid.org/0000-0003-4544-1750

\section{REFERENCES}

1. Ito Y, Miyauchi A, Inoue H, Fukushima M, Kihara M, Higashiyama T, et al. An observational trial for papillary thyroid microcarcinoma in Japanese patients. World J Surg 2010;34:28-35.

2. Ito Y, Uruno T, Nakano K, Takamura Y, Miya A, Kobayashi $\mathrm{K}$, et al. An observation trial without surgical treatment in patients with papillary microcarcinoma of the thyroid. Thyroid 2003;13:381-7.

3. Sugitani I, Toda K, Yamada K, Yamamoto N, Ikenaga M, Fujimoto Y. Three distinctly different kinds of papillary thyroid microcarcinoma should be recognized: our treatment strategies and outcomes. World J Surg 2010;34:1222-31.

4. Haugen BR, Alexander EK, Bible KC, Doherty GM, Mandel SJ, Nikiforov YE, et al. 2015 American Thyroid Association Management guidelines for adult patients with thyroid nodules and differentiated thyroid cancer: the American Thyroid Association Guidelines task force on thyroid nod-

Copyright (C) 2021 Korean Endocrine Society 
ules and differentiated thyroid cancer. Thyroid 2016;26:1133.

5. Jeon MJ, Kim WG, Chung KW, Baek JH, Kim WB, Shong YK. Active surveillance of papillary thyroid microcarcinoma: where do we stand? Eur Thyroid J 2019;8:298-306.

6. Cho SJ, Suh CH, Baek JH, Chung SR, Choi YJ, Chung KW, et al. Active surveillance for small papillary thyroid cancer: a systematic review and meta-analysis. Thyroid 2019;29:1399408.

7. Brito JP, Ito Y, Miyauchi A, Tuttle RM. A clinical framework to facilitate risk stratification when considering an active surveillance alternative to immediate biopsy and surgery in papillary microcarcinoma. Thyroid 2016;26:144-9.

8. Chen RC, Rumble RB, Loblaw DA, Finelli A, Ehdaie B, Cooperberg MR, et al. Active surveillance for the management of localized prostate cancer (Cancer Care Ontario Guideline): American Society of Clinical Oncology clinical practice guideline endorsement. J Clin Oncol 2016;34:218290.

9. Yi KH. The revised 2016 Korean Thyroid Association guidelines for thyroid nodules and cancers: differences from the 2015 American Thyroid Association Guidelines. Endocrinol Metab (Seoul) 2016;31:373-8.

10. Sugitani I, Ito Y, Takeuchi D, Nakayama H, Masaki C, Shindo $\mathrm{H}$, et al. Indications and strategy for active surveillance of adult low-risk papillary thyroid microcarcinoma: consensus statements from the Japan Association of Endocrine Surgery task force on management for papillary thyroid microcarcinoma. Thyroid 2021;31:183-92.

11. Hughes DT, Reyes-Gastelum D, Ward KC, Hamilton AS, Haymart MR. Barriers to the use of active surveillance for thyroid cancer: results of a physician survey. Ann Surg 2020 Oct 16 [Epub]. https://doi.org/10.1097/SLA.0000000000004417.

12. Ito Y, Miyauchi A, Kihara M, Higashiyama T, Kobayashi K, Miya A. Patient age is significantly related to the progression of papillary microcarcinoma of the thyroid under observation. Thyroid 2014;24:27-34.

13. Fukuoka O, Sugitani I, Ebina A, Toda K, Kawabata K, Yamada K. Natural history of asymptomatic papillary thyroid microcarcinoma: time-dependent changes in calcification and vascularity during active surveillance. World J Surg 2016;40: 529-37.

14. Tuttle RM, Fagin JA, Minkowitz G, Wong RJ, Roman B, Patel S, et al. Natural history and tumor volume kinetics of papillary thyroid cancers during active surveillance. JAMA Otolaryngol Head Neck Surg 2017;143:1015-20.
15. Oh HS, Ha J, Kim HI, Kim TH, Kim WG, Lim DJ, et al. Active surveillance of low-risk papillary thyroid microcarcinoma: a multi-center cohort study in Korea. Thyroid 2018;28: 1587-94.

16. Molinaro E, Campopiano MC, Pieruzzi L, Matrone A, Agate $\mathrm{L}$, Bottici $\mathrm{V}$, et al. Active surveillance in papillary thyroid microcarcinomas is feasible and safe: experience at a single Italian center. J Clin Endocrinol Metab 2020;105:e172-80.

17. Oh HS, Park S, Kim M, Kwon H, Song E, Sung TY, et al. Young age and male sex are predictors of large-volume central neck lymph node metastasis in clinical n0 papillary thyroid microcarcinomas. Thyroid 2017;27:1285-90.

18. Koshkina A, Fazelzad R, Sugitani I, Miyauchi A, Thabane L, Goldstein DP, et al. Association of patient age with progression of low-risk papillary thyroid carcinoma under active surveillance: a systematic review and meta-analysis. JAMA Otolaryngol Head Neck Surg 2020;146:552-60.

19. Miyauchi A, Kudo T, Ito Y, Oda H, Sasai H, Higashiyama T, et al. Estimation of the lifetime probability of disease progression of papillary microcarcinoma of the thyroid during active surveillance. Surgery 2018;163:48-52.

20. Lupoli G, Vitale G, Caraglia M, Fittipaldi MR, Abbruzzese A, Tagliaferri P, et al. Familial papillary thyroid microcarcinoma: a new clinical entity. Lancet 1999;353:637-9.

21. Capezzone M, Secchi C, Fralassi N, Cantara S, Brilli L, Ciuoli C, et al. Should familial disease be considered as a negative prognostic factor in micropapillary thyroid carcinoma? J Endocrinol Invest 2019;42:1205-13.

22. Shindo H, Amino N, Ito Y, Kihara M, Kobayashi K, Miya A, et al. Papillary thyroid microcarcinoma might progress during pregnancy. Thyroid 2014;24:840-4.

23. Ito Y, Miyauchi A, Kudo T, Ota H, Yoshioka K, Oda H, et al. Effects of pregnancy on papillary microcarcinomas of the thyroid re-evaluated in the entire patient series at Kuma hospital. Thyroid 2016;26:156-60.

24. Oh HS, Kim WG, Park S, Kim M, Kwon H, Jeon MJ, et al. Serial neck ultrasonographic evaluation of changes in papillary thyroid carcinoma during pregnancy. Thyroid 2017;27: 773-7.

25. Chung SR, Baek JH, Choi YJ, Sung TY, Song DE, Kim TY, et al. Sonographic assessment of the extent of extrathyroidal extension in thyroid cancer. Korean J Radiol 2020;21:118795.

26. Ito Y, Miyauchi A, Oda H, Kobayashi K, Kihara M, Miya A. Revisiting low-risk thyroid papillary microcarcinomas resected without observation: was immediate surgery neces- 
sary? World J Surg 2016;40:523-8.

27. Ito Y, Oda H, Miyauchi A. Insights and clinical questions about the active surveillance of low-risk papillary thyroid microcarcinomas [Review]. Endocr J 2016;63:323-8.

28. Lee DH, Kim YK, Yu HW, Choi JY, Park SY, Moon JH. Computed tomography for detecting cervical lymph node metastasis in patients who have papillary thyroid microcarcinoma with tumor characteristics appropriate for active surveillance. Thyroid 2019;29:1653-9.

29. Jeon MJ, Kim WG, Choi YM, Kwon H, Lee YM, Sung TY, et al. Features predictive of distant metastasis in papillary thyroid microcarcinomas. Thyroid 2016;26:161-8.

30. Kawano S, Miyauchi A, Ito Y. Routine chest computed tomography at presentation does not identify distant metastasis in cT1aN0 papillary thyroid carcinoma. Thyroid 2020;30: $1620-4$.

31. Kwon H, Oh HS, Kim M, Park S, Jeon MJ, Kim WG, et al. Active surveillance for patients with papillary thyroid microcarcinoma: a single center's experience in Korea. J Clin Endocrinol Metab 2017;102:1917-25.

32. Moon JH, Kim JH, Lee EK, Lee KE, Kong SH, Kim YK, et al. Study protocol of multicenter prospective cohort study of active surveillance on papillary thyroid microcarcinoma (MAeSTro). Endocrinol Metab (Seoul) 2018;33:278-86.

33. Sawka AM, Ghai S, Yoannidis T, Rotstein L, Gullane PJ, Gilbert RW, et al. A prospective mixed-methods study of decision-making on surgery or active surveillance for low-risk papillary thyroid cancer. Thyroid 2020;30:999-1007.

34. Tanaka A, Hirokawa M, Higuchi M, Suzuki A, Yamao N, Hayashi T, et al. Diagnostic clues indicating tall cell variants of papillary thyroid carcinoma in fine needle aspiration. Diagn Cytopathol 2019;47:452-7.

35. Ito Y, Miyauchi A, Kudo T, Higashiyama T, Masuoka H, Kihara $\mathrm{M}$, et al. Kinetic analysis of growth activity in enlarging papillary thyroid microcarcinomas. Thyroid 2019;29:176573.

36. Oh HS, Kwon H, Song E, Jeon MJ, Kim TY, Lee JH, et al. Tumor volume doubling time in active surveillance of papillary thyroid carcinoma. Thyroid 2019;29:642-9.

37. Kim HI, Jang HW, Ahn HS, Ahn S, Park SY, Oh YL, et al. High serum TSH level is associated with progression of papillary thyroid microcarcinoma during active surveillance.
J Clin Endocrinol Metab 2018;103:446-51.

38. Yabuta T, Matsuse M, Hirokawa M, Yamashita S, Mitsutake $\mathrm{N}$, Miyauchi A. TERT promoter mutations were not found in papillary thyroid microcarcinomas that showed disease progression on active surveillance. Thyroid 2017;27:1206-7.

39. Jeon MJ, Chung MS, Kwon H, Kim M, Park S, Baek JH, et al. Features of papillary thyroid microcarcinoma associated with lateral cervical lymph node metastasis. Clin Endocrinol (Oxf) 2017;86:845-51.

40. Sakai T, Sugitani I, Ebina A, Fukuoka O, Toda K, Mitani H, et al. Active surveillance for T1bN0M0 papillary thyroid carcinoma. Thyroid 2019;29:59-63.

41. Cheng SP, Lee JJ, Chien MN, Kuo CY, Jhuang JY, Liu CL. Lymphovascular invasion of papillary thyroid carcinoma revisited in the era of active surveillance. Eur J Surg Oncol 2020;46(10 Pt A):1814-9.

42. Kwon H, Jeon MJ, Kim WG, Park S, Kim M, Song DE, et al. A comparison of lobectomy and total thyroidectomy in patients with papillary thyroid microcarcinoma: a retrospective individual risk factor-matched cohort study. Eur J Endocrinol 2017;176:371-8.

43. Jeon MJ, Kang YE, Moon JH, Lim DJ, Lee CY, Lee YS, et al. Protocol for a Korean Multicenter Prospective Cohort Study of Active Surveillance or Surgery (KoMPASS) in papillary thyroid microcarcinoma. Endocrinol Metab (Seoul) 2021;36:359-64.

44. Cho SJ, Baek JH, Chung SR, Choi YJ, Lee JH. Thermal ablation for small papillary thyroid cancer: a systematic review. Thyroid 2019;29:1774-83.

45. Teng DK, Li WH, Du JR, Wang H, Yang DY, Wu XL. Effects of microwave ablation on papillary thyroid microcarcinoma: a five-year follow-up report. Thyroid 2020;30:1752-8.

46. Cho SJ, Baek SM, Lim HK, Lee KD, Son JM, Baek JH. Long-term follow-up results of ultrasound-guided radiofrequency ablation for low-risk papillary thyroid microcarcinoma: more than 5 -year follow-up for 84 tumors. Thyroid 2020;30:1745-51.

47. Roman BR, Gupta P, Tuttle RM, Morris LG, Lohia S. Assessing the number of candidates there are for active surveillance of low-risk papillary thyroid cancers in the US. JAMA Otolaryngol Head Neck Surg 2020;146:585-6. 